\title{
A INDIVIDUALIDADE EM SIMMMEL E ELIAS: CONTRIBUIÇÕES TEÓRICAS PARA UMA SOCIOLOGIA DO INDIVÍDUO
}

\author{
Ana Rodrigues Cavalcanti Alves \\ é doutoranda em Sociologia pelo Programa de Pós-Graduação em Sociologia da Universidade \\ Federal de Pernambuco (UFPE) e professora temporária do Departamento de Sociologia da UFPE. \\ Recife, PE, Brasil. E-mail: <anarodrigues86@gmail.com>. \\ Louise Claudino Maciel \\ é doutoranda em Sociologia pelo Programa de Pós-Graduação em Sociologia da Universidade \\ Federal de Pernambuco (UFPE).Recife,PE, Brasil. E-mail: <louiseclaudino@yahoo.com.br>.
}

http://dx.doi.org/10.1590/0102-259290/101

Muitas correntes da teoria social contemporânea têm sido marcadas por um crescente interesse pelo indivíduo na compreensão dos fenômenos sociais, devido ao reconhecimento das mudanças ocorridas, sobretudo, a partir da segunda metade do século XX, que conduziram a uma transformação fundamental na relação entre indivíduo e sociedade. Se a consolidação da sociologia como disciplina autônoma se caracterizou por um esforço em desvendar as determinações sociais na explicação da vida social, o crescente processo de individualização observado nas sociedades modernas - intensificado a partir dos anos 1960 - coloca em xeque as formas de pensar a sociedade e de fazer sociologia.

Segundo Martuccelli e Singly (2012), nas sociedades contemporâneas, não é possível definir os indivíduos sociais apenas por um pertencimento típico (classe social, gênero, raça, idade), de modo que é necessário prestar mais atenção no trabalho que esse indivíduo realiza sobre si mesmo. Partindo dessa perspectiva, desenvolveu-se, nas últimas décadas, uma corrente teórica que defende a necessidade de conferir mais espaço ao indivíduo na análise sociológica 
- a sociologia do indivíduo. Vale ressaltar que essa corrente teórica é formada por diferentes perspectivas. Das quatro vertentes que Martuccelli e Singly (2012) afirmam compor esse campo, interessa neste artigo a vertente representada pelas obras de Jean-Claude Kaufmann e Bernard Lahire. Tal vertente aborda o ator social como resultado de um conjunto de processos socializantes que transmitem ao indivíduo disposições múltiplas e plurais ${ }^{1}$.

Embora a sociologia do indivíduo seja constituída por uma diversidade de perspectivas, todas elas partem de uma crítica segundo a qual a sociologia sempre tentou compreender a vida social a partir da identificação das lógicas grupais dos grandes processos estruturais, ou seja, a partir de noções como a de grupo, de classe social, de civilização, de Estado-nação etc. Segundo Martuccelli (2007), nenhum outro modelo resumiu melhor esse projeto do que a noção de "personagem 260 social", que tenta compreender as ações e experiências dos indivíduos a partir de sua posição social, fazendo dele um exemplar único e típico das diferentes camadas sociais. A teoria de Pierre Bourdieu constitui um dos principais exemplos desse modelo, na qual a posição ocupada no espaço social determina todas as condutas e vivências do indivíduo nas mais diversas esferas da vida social.

Os teóricos da nova abordagem reconhecem que, apesar de a sociologia ter adotado predominantemente o modelo do personagem social em suas análises, o

\footnotetext{
1 Uma segunda vertente, caracterizada pela obra de Ehrenberg, aborda como nas sociedades atuais o indivíduo é produzido por instituições sociais que conduzem à sua responsabilização no que refere a uma gama de esferas da vida (Ehrenberg, 2010). Uma terceira vertente, na qual os autores localizam a obra de Singly, enfatiza as dimensões relacionais do sujeito. Por fim, a vertente da sociologia das provas, à qual Martuccelli (2007) vincula o seu trabalho, lança mão da noção de prova para compreender os processos de individuação presentes na sociedade contemporânea (Martuccelli e Singly, 2012).
} 
indivíduo jamais esteve completamente ausente da sociologia clássica, haja vista que o nascimento da sociologia é concomitante ao nascimento do indivíduo na modernidade. Sempre houve um interesse, por parte de seus melhores teóricos, pela análise das dimensões individuais. Dentre os clássicos, Georg Simmel foi o que mais se preocupou em construir uma teoria sociológica do individualismo que lida tanto com as concepções ideológicas sobre a individualidade na modernidade (tipos de individualismo) como com a relação entre fenômenos tipicamente modernos tais como a economia monetária, a divisão social do trabalho, a ampliação e cruzamento dos círculos sociais, e a individualidade. Simmel foi um dos primeiros sociólogos a adotar uma perspectiva relacional do social - buscando superar a dicotomia entre indivíduo e sociedade -, o que lhe permitiu pensar a individualidade como um fenômeno, ligado às mudanças no padrão de relações sociais, que caracteriza a modernização da sociedade. Desse modo, o autor desponta como uma importante referência teórica para a então emergente sociologia do indivíduo.

De modo semelhante, Norbert Elias parte de uma concepção processual do social, encontrada na obra de Simmel, desenvolvendo uma noção de individualidade que remete à moldagem e diferenciação das funções mentais do indivíduo sempre no interior de uma rede de relações (figuração). Nesse sentido, essa individualidade é sempre, por um lado, típica, pois ela é produto de uma moldagem realizada no interior de uma rede de relações específica, e, por outro, singular, pois nunca é idêntica de um indivíduo a outro. Essa concepção processual do social tem sido mobilizada por diversas correntes da sociologia contemporânea na empreitada de romper com a visão do mundo social como constituído 
por entidades relativamente estáveis, sejam agentes humanos ou estruturas sociais. Para eles, a sociedade seria o resultado de relações entre indivíduos e grupos, algo que deve ser produzido e conectado incessantemente. Nessa perspectiva, a individualidade também figura como um processo aberto, na medida em que se nega a noção do indivíduo autossustentado e fixo.

Esse artigo explora a importância que as concepções de individualidade desenvolvidas por Simmel e Elias possuem no desenvolvimento de uma sociologia do indivíduo, sobretudo, nos trabalhos de Kaufmann e Lahire. A ideia central defendida neste trabalho é a de que os referidos autores retomam o conceito de individualidade desenvolvido pelos clássicos na formulação de suas críticas ao pensamento de Bourdieu e nas suas análises dos processos de individualização na sociedade contemporânea. A peculiaridade com que a sociologia 262 lida com os autores clássicos já foi amplamente debatida na literatura. Os trabalhos de Kaufmann e de Lahire podem ser analisados a partir de uma perspectiva presentista, uma vez que eles interpelam as obras de Simmel e de Elias partindo de um ponto de vista contemporâneo ${ }^{2}$. Como afirma Pyyhtinen (2010, p. 11), "presentistas usam as conceitualizações, temas e teorias formuladas pelos clássicos para seus próprios

\footnotetext{
2 Pyyhtinen (2010) diferencia as três posições que são comumente encontradas em torno do lugar que os textos clássicos devem possuir na disciplina. A primeira, representada pelo positivismo, opõe-se à centralidade que esses textos ainda possuem nessa ciência. Os positivistas sustentam que uma parte significativa das teorias clássicas não pode ser empiricamente verificada e que outra parte mostrou-se empiricamente insustentável, de modo que sua interpretação deveria perder lugar em prol do conhecimento empírico. O historicismo defende um lugar para os textos clássicos na sociologia, mas argumenta que eles devem ser interpretados apenas em termos históricos, dentro dos seus limites contextuais. Na contramão dessas perspectivas, o presentismo afirma que os autores clássicos são relevantes para os sociólogos não só em sentido histórico, mas em sentido sociológico. A localização histórica das obras clássicas é menos importante do que a comunalidade das preocupações sociológicas que dividem com os contemporâneos (Baehr, 2002).
} 
propósitos, projetando seus próprios problemas sobre eles e tentando entender o mundo contemporâneo que vivemos com a ajuda deles".

Dentre os elementos mais importantes dessa interlocução, encontra-se a perspectiva relacional e processual sobre a individualidade desenvolvida nos trabalhos de Simmel e de Elias, que é resgatada pelos autores para analisar a produção da individualidade nas sociedades contemporâneas como um processo constante de incorporação de disposições múltiplas, plurais e até mesmo contraditórias, fortemente caracterizado pela necessidade constante do trabalho do indivíduo sobre si mesmo.

\section{O social em Simmel e em Elias: uma alternativa à dicotomia entre indivíduo e sociedade}

É importante destacar que se Simmel e Elias desenvolveram concepções de individualidade que garantem sua centralidade nos debates contemporâneos sobre o indivíduo e sua relação com o social, tais concepções estão estreitamente ligadas às suas posições epistemológicas, que contrastam diretamente com a perspectiva sociológica dominante em sua época. A predominância de uma imagem estática e onipotente da sociedade no pensamento sociológico remonta ao período de seu surgimento e formação no início do século XIX. A própria sociologia nasce, em certa medida, como uma reação ao individualismo pregado pelo Iluminismo e pela Revolução Francesa, fortemente influenciada pelo conservantismo. Se o Iluminismo pregava valores como a razão, a igualdade e a liberdade individual, os conservadores criticavam o individualismo e tomavam a sociedade como ponto de partida, modeladora e formadora do indivíduo. É possível perceber a influência desse movimento em pensadores como Durkheim, que se empenha ao longo de toda a sua obra em 
estabelecer os fundamentos da sociologia como disciplina autônoma ao desvendar o peso do social sobre as condutas individuais, mesmo aquelas consideradas mais particulares ou egoístas, como o suicídio (Nisbet, 1980, p. 134).

Na contramão dessa perspectiva, Simmel e Elias partem de uma abordagem que focaliza as relações sociais em detrimento da noção de sociedade como uma realidade estática. Embora tanto um quanto outro neguem a concepção da sociedade como uma entidade acabada e autônoma aos indivíduos, com seus mecanismos próprios de desenvolvimento, não partilham da concepção de que os fenômenos sociais devem ser remetidos às ações, concepções e comportamentos dos atores individuais. Eles adotam uma perspectiva relacional do social, como meio de superar a oposição entre indivíduo e sociedade, buscando construir um aparato conceitual que apreenda a natureza dinâmica das relações sociais.

Na concepção de Simmel (1983), uma sociedade existe 264 sempre que vários indivíduos estejam em reciprocidade de ação, constituindo uma unidade, seja esta permanente ou passageira. Unidade aqui não se refere apenas à concordância e ao consenso dos indivíduos, uma vez que, para Simmel, o conflito é tido como forma de sociação. A sociedade é um processo extremamente dinâmico de emergência, decadência e reemergência das formas de sociação, a exemplo da competição, da cooperação, da refeição, da sociabilidade, da moda, entre inúmeras outras. Segundo o autor, se uma ou mais de tais formas desaparecem, a sociedade continuará existindo, mas se todas as formas desaparecem, a sociedade também entra em declínio, haja vista que sem as formas de sociação, os indivíduos não podem evidenciar o conteúdo dos sentimentos que os estimulam.

Como afirma Waizbort (2001, p. 99), em Simmel, o todo consiste na interação entre as partes e na medida em que essa interação é múltipla e constante, esse todo é móvel e está sempre em processo, como um "tecido que se tece 
continuamente". Nesse sentido, Simmel prefere o termo sociação à sociedade, porque o primeiro tende a enfatizar o elemento processual do social, enquanto o segundo nos dá a ideia de algo pronto e estático. Para Simmel, a sociedade não consiste em uma realidade autônoma, com leis próprias e mecanismos de funcionamento independente dos indivíduos, nas palavras do autor,

não há sociedade absoluta, no sentido de que deveria existir como condição prévia para que surjam esses diversos fenômenos de união; pois não há interação absoluta, mas somente diversas modalidades dela, cuja emergência determina a existência da sociedade, da qual não são nem causa nem efeito, mas ela própria de maneira imediata. Somente a extraordinária pluralidade e variedade destas formas de interação a cada momento emprestam uma aparente realidade histórica autônoma ao conceito geral de sociedade (Simmel, 1983, p. 65).

Tal formulação do social possui muitas afinidades com a desenvolvida na obra de Norbert Elias, que enfatiza os processos de constituição do social, em oposição aos seus estados fixos e acabados. Elias (2011, p. 224) aponta os contrassensos contidos na noção de "sistema social", presente no pensamento de Parsons e predominante na sociologia de sua época. Segundo ele, essa noção remete à ideia de uma sociedade "em equilíbrio", que existe em estado de repouso, sendo as contradições e tensões que se manifestam na vida social percebidas como disfunções. Por outro lado, o autor critica as abordagens que concebem os indivíduos como inteiramente livres e independentes; como personalidades "fechadas", autossuficientes "por dentro" e separada dos demais (Elias, 2011, p. 228).

$\mathrm{O}$ autor busca substituir os conceitos de sociedade e de indivíduo como objetos separados, independentes e em 
estado de repouso. Para Elias (2011, p. 240), tais conceitos correspondem a aspectos diferentes, embora inseparáveis, dos mesmos seres humanos, que precisam ser revestidos do caráter de processo na teoria sociológica, entendidos como entidades em mutação. A ideia do indivíduo como "personalidade fechada" é substituída pela de "personalidade aberta", que possui maior ou menor grau de autonomia em face de outras pessoas e que é sempre orientada para outras pessoas e dependente delas. $\mathrm{O}$ autor destaca a importância das relações para a própria composição do indivíduo, devido à sua dependência natural do convívio com outras pessoas.

Elias desenvolve a noção de figuração como ferramenta que permite apreender a dimensão processual e relacional do social. Tal noção desvela essa rede de interdependências, ou seja, de funções que as pessoas necessariamente cumprem umas com as outras na sociedade. Nas suas palavras,

é a essa rede de funções que as pessoas desempenham umas em relação às outras, a ela e nada mais que chamamos "sociedade". Ela representa um tipo especial de esfera. Suas estruturas são o que denominamos "estruturas sociais". E, ao falarmos em "leis sociais" ou "regularidades sociais", não nos referimos a outra coisa senão isto: às leis autônomas das relações entre as pessoas individualmente consideradas (Elias, 1994, p. 23).

Para o autor, falta ao pensamento sociológico modelos conceituais que permitam pensar as noções de indivíduo e sociedade não como substâncias, independentemente de suas relações. São as próprias relações que possuem estruturas e regularidades próprias, uma vez que os comportamentos e as ações humanas não decorrem de um substrato natural e biológico fixo, "as regularidades ou leis nascidas do entrelaçamento e da interdependência dos indivíduos assumem sua plena força" (Elias, 1994, p. 39). Para Elias, a vida social 
é composta do entrelaçamento de indivíduos interdependentes. Nessa perspectiva, os seres humanos são conceitualizados como interdependentes e não como autônomos (Van Krieken, 1998). Quaisquer que sejam os fenômenos que pretendemos investigar devemos partir dessas redes de relações e não dos indivíduos isolados. Portanto, para compreender a individualidade enquanto fenômeno social, caberia questionar os tipos de relações que a produzem. Nas próximas seções, será discutida a concepção de individualidade presente nas obras de Simmel e Elias, bem como o padrão de relações sociais que permite a sua potencialização na modernidade.

\section{Relações sociais e individualidade em Simmel}

De acordo com Simmel (2005), a modernidade foi palco de emergência de duas modalidades de individualismo, desenvolvidas na cultura europeia a partir do século XVIII, e fundamentadas em duas concepções distintas de liberdade. A primeira noção de individualismo desenvolve-se a partir do século XVIII, imbuída por um ideal de liberdade individual caracterizado pela liberação do indivíduo das instituições religiosas, políticas e econômicas que constrangem os potenciais da personalidade de maneira não natural. É necessário, portanto, libertá-lo de todas essas influências e das desigualdades artificialmente produzidas para que o indivíduo possa desenvolver todos os valores internos e externos de sua personalidade. Essa concepção de individualismo tinha como fundamento a igualdade universal, seja esta fundada na natureza, na razão ou na humanidade. O centro do interesse dessa época é o homem abstrato, que constitui a essência de qualquer pessoa particular, ao contrário do homem historicamente situado, singularizado e diferenciado pelos seus pertencimentos sociais. Há uma relação de pertencimento prévio entre direito, liberdade e igualdade. 
O autor adverte que, na prática, essa concepção de individualidade implica que as relações humanas não necessitariam de intervenções reguladoras especiais, já que todos os homens seriam iguais em essência e capazes de um desenvolvimento perfeito. Apesar disso, a igualdade continuou a se manifestar de maneira muito imperfeita na realidade, o que conduziu ao questionamento de sua necessária relação com a liberdade. Em decorrência dessa contradição entre liberdade e igualdade, que passou despercebida durante o século XVIII, surge no século XIX outra concepção de individualismo que atribui ênfase à desigualdade. A liberdade permanece como o denominador comum também com o correlato oposto.

Contudo, é importante destacar que se, por um lado, Simmel (2005, p. 112) aponta a contraposição entre as duas concepções de individualismo, por outro, ele busca apreender sua articulação, mostrando que o individualismo do 268 século XIX pressupõe a concepção do século XVIII. Nas suas palavras, "tão logo o eu, no sentimento da igualdade e universalidade, sentiu-se forte o bastante, passou a procurar a desigualdade, mas apenas aquela que surgia como uma lei interna". Após a libertação dos indivíduos de suas antigas dependências históricas, o movimento segue adiante e esses indivíduos tornados autônomos buscam agora distinguir-se entre si. O importante não é o indivíduo como tal, mas sim o que este tem de único e distinto. Desse modo, intensifica-se a procura moderna pela diferenciação, a busca do indivíduo por si mesmo, por um ponto de solidez e ausência de dúvidas, que se torna tanto mais necessária quanto maior a complexidade da vida. E essa busca não pode ser encontrada em instâncias externas à própria alma, embora as relações com os outros sejam fundamentais nesse processo.

Segundo o autor, a primeira concepção de individualismo é o produto do liberalismo racional da Inglaterra e da França, enquanto a segunda é uma criação do espírito 
germânico, desenvolvida no seio do romantismo alemão. Embora em constante tensão, o autor afirma que essas duas grandes forças da cultura moderna procuram um equilíbrio nas mais diversas esferas. No entanto, até o século XIX, os dois tipos de individualismo só foram unidos na constituição de princípios econômicos. Nessa esfera, a concepção da liberdade e da igualdade fundamenta a livre concorrência, enquanto a personalidade diferenciada é o fundamento da divisão do trabalho.

A concepção de individualidade desenvolvida por Simmel mescla elementos das duas modalidades de individualismo referidas. Ela remete à libertação do indivíduo das formas de vida comunitárias que limitavam a liberdade pessoal e a autodeterminação do mesmo, assim como ao crescente processo de singularização dos indivíduos, potencializado por determinados fenômenos característicos da modernidade. Simmel se debruça sobre as mudanças no padrão de relações sociais que permitiram o surgimento dessa individualidade. Em Filosofia do dinheiro, o autor mostra como o desenvolvimento de uma economia monetária possibilitou uma margem crescente de liberdade individual e, consequentemente, um maior domínio da consciência pelo indivíduo. De acordo com Simmel (1977, p. 348), a economia monetária conduziu a uma maior objetividade das relações sociais. $\mathrm{O}$ dinheiro possibilita a adoção de um critério quantitativo na apreensão dos produtos, reduzindo toda qualidade e individualidade à questão: "quanto?". Portanto, nos mais diversos fenômenos, dentro da economia monetária, os objetos tornam-se cada vez mais indiferentes em sua singularidade e individualidade, carentes de essência e intercambiáveis.

O princípio da objetividade adotado pela economia monetária também conduziu a uma transformação da forma real que tomam as relações de dependência, possibilitando o desenvolvimento da liberdade individual. Enquanto nas 
formações sociais anteriores, a vinculação e o direito do senhor abrangiam não apenas o produto do trabalho como também a personalidade do trabalhador, a economia do dinheiro conduz a uma separação completa da personalidade como tal frente às relações de dever. Não há uma subordinação a outra personalidade subjetiva, haja vista que o dinheiro despersonaliza as relações (Simmel, 1977, p. 338). Se o homem se torna mais dependente de uma grande quantidade de provedores, ele é muito mais independente da pessoa concreta que lhe presta um serviço, que pode ser substituída com facilidade.

A economia monetária facilita a separação do elemento pessoal das relações entre os seres humanos por meio de sua essência objetiva. Em consequência disso, o indivíduo desenvolve uma indiferença em relação às pessoas e, ao mesmo tempo, maior liberdade de intercâmbio com elas. Essa seria a situação mais favorável para desenvolver a individualidade, ou 270 seja, para ampliar o núcleo do eu por meio da vontade e sentimento individuais. Nas palavras de Simmel (1977, p. 358),

a causa e o efeito destas dependências objetivas, nas quais o sujeito como tal é livre, residem na trocabilidade das pessoas; na troca voluntária dos sujeitos ocasionada através da estrutura da relação se revela aquela indiferença do elemento subjetivo, que leva o sentimento da liberdade.

A personalidade surge, assim, como a contraposição subjetiva das circunstâncias de dependências objetivas e de indiferença impostas pela economia do dinheiro que conduz a um largo processo de diferenciação social, do qual resulta a acentuação da importância do eu, por um lado, e da coisa, por outro. Para Simmel (1977, p. 361), o surgimento da personalidade é, ao mesmo tempo, o processo de surgimento da liberdade - uma vez que tudo o que chamamos de personalidade (a unidade de elementos psíquicos, 
sua concentração em um só ponto, a insubstituibilidade de sua essência) implica também a independência e exclusão de todo o exterior - e o desenvolvimento de acordo com as leis da própria essência - a que se chama liberdade.

O crescimento dos círculos sociais também é percebido por Simmel como uma importante transformação para o aumento da liberdade e da individualidade. De acordo com o autor, uma das poucas regras que se pode estabelecer, com universalidade, acerca da evolução social é a de que a extensão de um grupo é paralela à individualização e independência de seus membros isolados. Nas suas palavras,

a evolução das sociedades costuma começar com um grupo relativamente pequeno, que mantém seus elementos em estreita vinculação e igualdade e avança para um grupo mais amplo que garante liberdade, autonomia e diferenciação recíproca de seus elementos (Simmel, 1977, p.422).

Simmel (2009) contrasta a situação na qual o indivíduo está vinculado a um único círculo estreito com aquela em que o indivíduo se encontra no ponto de cruzamento de vários círculos. Na primeira situação, o indivíduo se encontra em um meio que é indiferente à sua individualidade e que lhe impõe que ele viva estreitamente ligado àqueles aos quais se encontra vinculado por nascimento, por localidade, dentre outros critérios de vinculação obrigatórios. Tal situação é muito diferente daquilo que caracteriza as associações modernas. Essas permitem que os indivíduos participem de tantas associações quantas lhe agradem. Essa situação potencializa mais espaço para a individualidade, já que pertencendo a inúmeros círculos, o indivíduo não está por inteiro em nenhum desses. Portanto, a dependência em relação a muitos círculos, em oposição a uma dependência em relação a um círculo estreito atua como um catalisador da liberdade individual. 
A tendência para o crescimento da individualidade não consiste em se abolir o laço social, mas tornar um fator de liberdade o processo de escolha a quem ou ao que o indivíduo se vincula. Diferentemente dos laços compulsórios que se estabelecem sem a participação do sujeito, o autor acreditava que as associações modernas se sustentam nos interesses e desejos dos próprios indivíduos. Deve-se frisar, também, que o cruzamento dos círculos sociais que se dá no indivíduo, característico da modernidade, está fortemente relacionado com um componente importante da noção de individualidade, a saber: a singularidade e especificidade de uma pessoa em relação às demais.

O pertencimento a muitos círculos sociais abre, segundo Simmel (2009), a possibilidade de infinitas combinações individualizantes. Há poucas chances que mais de um indivíduo participe do mesmo conjunto de círculos sociais e na mesma intensidade. $\mathrm{O}$ autor compreende os grupos nos 272 quais o indivíduo atua como um sistema de coordenadas, de modo que a cada círculo social que o indivíduo adentra, e que é somado aos círculos antigos, sua individualidade fica determinada de modo mais preciso. A subjetividade, para ele, consiste nas combinações e sínteses que cada um realiza a partir de diversos elementos da cultura e da sociedade. Para o autor, o pertencimento do indivíduo a uma pluralidade de círculos sociais pode engendrar conflitos tanto internos como externos. Contudo, esse pertencimento também possui um efeito estabilizador, reforçando a unidade do indivíduo e a necessidade de autodeterminação.

Simmel é tido como um dos precursores da sociologia do indivíduo por tentar integrar, na sua análise das transformações sociais, a compreensão sobre as condições psicológicas advindas com a modernidade. Para ele, o fenômeno psíquico que melhor expressa a vida na metrópole é a atitude blasé, que consiste numa reação aos estímulos contrastantes que são continuamente impostos aos nervos, atuando como 
uma espécie de filtro e de recusa aos mesmos. Tal atitude expressa a relação entre uma estrutura da mais alta impessoalidade e, em contraposição, uma subjetividade altamente pessoal. Mas essa fonte fisiológica da atitude blaséé acrescida de outra que flui da economia do dinheiro e corresponde ao embotamento do poder de discriminar toda qualidade dos objetos, de modo que nenhum objeto merece preferência sobre outro. Para Simmel (1987, p. 16), "esse estado de ânimo é o fiel reflexo subjetivo da economia do dinheiro completamente interiorizada”.

O caráter objetivo da economia do dinheiro conduz a uma objetivação crescente de conteúdos existenciais e favorece a exclusão daqueles impulsos irracionais e instintivos, que tentam determinar o modo de vida de dentro, ao invés de receber a forma de vida geral de fora. Assim, há uma maior complexificação do indivíduo, que o conduz a um maior grau de consciência. Ele não se deixa levar por impulsos inconscientes, mas orienta a sua ação conforme as exigências da vida social.

De acordo com Simmel (2005), a metrópole é o lugar por excelência do encontro e da tensão entre as duas formas de individualismo que emergiram na modernidade. As relações de troca que predominam na metrópole baseiam-se na premissa da universalidade do ser humano. Por outro lado, em meio à constante quantificação e padronização dos objetos, os indivíduos buscam exacerbar seus traços singulares. A pessoa se volta para diferenças qualitativas, buscando atrair de alguma forma a atenção do círculo social, explorando sua sensibilidade e diferenças. Esse processo é reforçado pela divisão do trabalho, que compele o indivíduo a se especializar em uma função na qual não possa ser prontamente substituído por outros.

Martuccelli e Singly (2012, p. 23) destacam que a individualidade para Simmel decorre tanto de condições externas, como o pertencimento a diversos círculos sociais separados 
entre si, quanto do trabalho interior, íntimo. Sua concepção de individualidade se torna central para a sociologia do indivíduo desenvolvida um século depois, porque ele enfatiza, por um lado, a crescente divisão interna dos indivíduos e a independência entre as diversas partes de seu ser e, por outro lado, a existência de um conflito interior entre essas partes. Apesar da sua contribuição teórica, Simmel foi praticamente esquecido depois da Primeira Guerra Mundial e a maioria dos sociólogos abandonou a ênfase dos clássicos na importância das formações psicológicas particulares dos indivíduos na explicação da vida social. No entanto, Norbert Elias é um dos teóricos que mantém essa ênfase (Van Krieken, 1998, p. 44).

\section{A sociedade dos indivíduos de Elias}

Tal como em Simmel, a concepção de individualidade desenvolvida por Elias possui um componente sócio274 histórico. Segundo Elias (1994), nas sociedades tradicionais, o sentimento de pertencer a um grupo, seja a uma família, a uma tribo ou ao Estado tinha muito mais peso na vida dos indivíduos do que aquilo que eles concebiam como traços individuais de sua personalidade. Com a modernidade, essa identidade-nós foi deslocada pela identidade-eu que possibilitou a emergência da própria concepção de indivíduo. Esta última passa a "expressar a ideia de que todo ser humano do mundo é ou deve ser uma entidade autônoma e, ao mesmo tempo, de que cada ser humano é, em certos aspectos, diferente de todos os demais, e talvez deva sê-lo" (Elias, 1994, p. 130).

O esforço de Elias consiste em demonstrar que aquilo que singulariza os indivíduos em relação aos outros não pode ser tido como um elemento extrassocial, conceituado em termos naturais ou metafísicos. Para ele, o que é singular e diferente no indivíduo em relação aos outros, em suma, a sua individualidade, só pode ser compreendido 
adequadamente se voltarmos nossa atenção para as relações sociais. Há um longo processo de moldagem social que o indivíduo atravessa a fim de deixar a sua constituição primeira e adquirir sua individualidade.

Em O processo civilizador, Elias (2011) se debruça sobre a análise dos processos de sociogênese e de psicogênese desenvolvidos no curso da história humana, mostrando que as mudanças na estrutura da sociedade estão estreitamente ligadas a mudanças na estrutura e no comportamento da constituição psíquica. $\mathrm{O}$ autor destaca uma tendência de maior diferenciação e integração social no curso do processo civilizador, que é acompanhada por mudanças na estrutura da personalidade, caracterizadas por um maior controle das emoções e dos instintos.

Para ele, o caráter que a individualidade assume na modernidade é resultante desse longo processo, em que os indivíduos passam a exercer um crescente controle sobre si mesmos, atuando independentemente de agentes externos, por meio da internalização de normas sociais e padrões de comportamento na direção de uma autorregulação dos impulsos e instintos. Há uma transformação da compulsão externa interpessoal em compulsão interna individual, conduzindo a uma situação em que muitos impulsos afetivos não podem mais ser vivenciados tão espontaneamente como antes, sem a intervenção de mecanismos de controle (Elias, 2011, p. 236).

Portanto, a individualidade e as relações sociais não são termos antitéticos. Tal individualidade é conceituada por Elias (1994, p. 36) como a moldagem e diferenciação das funções mentais de uma pessoa, que apenas se desenvolve por meio da integração do indivíduo em uma rede formada por outros indivíduos. Nessa concepção, as funções psíquicas não possuem uma base biológica, mas social. $\mathrm{O}$ autor afirma que a diferenciação das funções mentais que denotamos com os conceitos de mente e alma, de razão e sentimento, de consciência e instinto e de id e ego, não surgem 
naturalmente nos indivíduos, paralelamente ao processo de seu desenvolvimento físico. Sendo essas funções mentais formas de autorregulação da pessoa em relação a outras pessoas e coisas, elas só podem se constituir em meio ao convívio social.

Segundo Elias (1994, p. 30), não é somente o comportamento consciente que é constantemente formado e transformado na criança por meio de suas relações com os outros, mas também seu comportamento controlado pelos instintos; embora esse comportamento nunca seja uma simples cópia do que é feito pelos outros, mas sua resposta à maneira como seus instintos e afetos, que se orientam para outras pessoas, são correspondidos por esses outros. Para o autor, a peculiaridade da própria natureza humana corresponde ao grau bastante elevado em que a autorregulação humana está livre do controle de mecanismos reflexos hereditários. É essa liberdade das predeterminações hereditárias no manejo das 276 relações pelo indivíduo que permite e, ao mesmo tempo, exige uma moldagem sociogênica das funções psíquicas. E é graças a essa moldagem social que a forma de autorregulação em relação aos outros é mais diversificada do que nos outros animais, ou seja, é mais individual.

É justamente pelo fato de os seres humanos estarem menos presos a leis organicamente prescritas que o entrelaçamento de suas atividades conduz a leis e estruturas de um tipo especial. Devido a essa peculiaridade da psique humana, sua maior maleabilidade e natural dependência da moldagem social, Elias (1994, p. 39) afirma que não é possível tomar indivíduos isolados para entender a estrutura da sociedade. A individualidade que o ser humano acaba por desenvolver depende de todo processo de individualização, de modo que as constituições naturais em bebês recém-nascidos podem levar a um desenvolvimento muito diferenciado da consciência e dos instintos, dependendo da estrutura de relações preexistentes em que elas cresçam. 
Para Elias (1994, p. 52), a noção de individualidade como expressão de um núcleo natural extrassocial dentro do indivíduo, no qual os traços sociais são depositados, está ligada a uma singular conformação histórica do indivíduo pela rede de relações, ou seja, por uma forma de convívio de uma estrutura muito específica. Por meio dessa estrutura, desenvolve-se a autoconsciência de pessoas que foram obrigadas a adotar um grau elevado de refreamento, de controle afetivo, de renúncia e transformação dos instintos, e que relegam muitas das suas funções, desejos e expressões instintivas a enclaves privativos de sigilo, afastados do olhar do mundo externo, ou até a um nível semiconsciente ou inconsciente.

Segundo Elias (1994, p. 32), "esse tipo de autoconsciência corresponde à estrutura psicológica estabelecida em certos estágios de um processo civilizador". Ela se caracteriza por uma intensa tensão e diferenciação entre as pulsões e instintos do indivíduo e as proibições e coerções sociais inculcadas como autodomínio. É esse conflito no interior do indivíduo que o leva a pensar que ele é algo que existe inteiramente só dentro de si e que só depois se relaciona com os outros do lado de fora. Esse abismo e intenso conflito que as pessoas fortemente individualizadas desse estágio de civilização sentem dentro de si é projetado no mundo por sua consciência e se reflete na discussão teórica como um abismo e eterno conflito entre indivíduo e sociedade.

Se Elias pensa os conflitos do indivíduo em termos de uma síntese entre o pensamento de Freud - que destaca os impulsos e instintos - e de Durkheim - que enfatiza as coerções do social sobre o indivíduo -, sua concepção de indivíduo também remete à noção de sujeito histórico de Marx, pois as contradições da vida social geram no indivíduo uma autoimagem ${ }^{3}$. Assim, Elias (1994, p. 53) afirma

\footnotetext{
3 No entanto, é importante destacar que, na concepção de Elias, esse sujeito histórico perde sua dimensão teleológica, o que o distancia da perspectiva historicista encontrada em Marx.
} 
que se a tensão e contradições entre os desejos do indivíduo parcialmente controlados pelo inconsciente, de um lado, e as exigências sociais representadas por seu superego, de outro, nunca estão completamente ausentes em nenhuma sociedade, elas se mostram especialmente intensas e difusas quando o processo civilizador atinge um estágio avançado.

Assim como Simmel, Elias relaciona esse desenvolvimento das funções psíquicas à crescente divisão do trabalho na sociedade moderna e ao consequente crescimento da interdependência entre as pessoas, que só podem sustentar sua vida em conjunto com muitas outras. As tarefas acessíveis à massa dos indivíduos numa sociedade com tantas tensões e uma divisão tão avançada do trabalho exigem uma especialização bastante estrita, enquanto o trabalho continua a consumir a maior parte do dia. Desse modo, tais tarefas deixam apenas um campo muito restrito e unilateral para as faculdades e inclinações do indivíduo, reforçando 278 ainda mais suas tensões e cisões intrapsíquicas. De acordo com Elias (1994, p. 33),

não apenas o alto grau de controle das transformações dos instintos, como também as limitações e a especialização impostas pelas funções adultas, a intensidade da competição e as tensões entre os vários grupos adultos, tudo isso torna especialmente difícil o condicionamento do indivíduo. A probabilidade de que ele fracasse em algum aspecto, de que o equilíbrio entre as inclinações pessoais e as tarefas sociais seja inatingível para o indivíduo torna-se bastante aguda.

Assim, os indivíduos sentem que para manter suas posições na rede humana precisam deixar fenecer sua verdadeira natureza, experienciando, assim, um verdadeiro abismo entre indivíduo e sociedade. Assim como Simmel, Elias chama atenção para as consequências negativas decorrentes de uma situação de concorrência e da crescente 
divisão do trabalho para o desenvolvimento de uma cultura interna. Ademais, ambos os autores destacam a existência de tensões e conflitos interiores que são constitutivos da individualidade. Mas enquanto Simmel aponta o crescimento dos círculos sociais como o principal fator responsável pela existência desses conflitos, Elias afirma que as tensões intrapsíquicas nunca estão completamente ausentes de nenhuma sociedade. Para ele, essas tensões correspondem à existência, por um lado, de pulsões e instintos do indivíduo controlados pelo inconsciente e, por outro lado, de exigências sociais representadas pelo seu superego. No entanto, Elias concorda com Simmel que essas tensões aparecem de maneira mais intensa quando o processo civilizador atinge um estágio mais avançado.

A diferença observada entre os enfoques teóricos dos autores corresponde mais a uma diferença do período histórico considerado em suas análises. Se Simmel concentra sua análise sobre a modernidade, Elias, por sua vez, parte de um estudo que busca remontar às origens do processo civilizador, colocando em perspectiva histórica mais ampla muitas das tendências à autorregulação do indivíduo, potencializadas na modernidade. No estágio mais avançado do processo civilizador, a individualidade emerge como uma peculiaridade das funções psíquicas do indivíduo. Ela corresponde à maneira em que a qualidade estrutural do controle psíquico de uma pessoa difere do de outras. E quanto mais diferenciada a estrutura funcional de uma sociedade, mais nitidamente divergem as configurações psíquicas de cada uma das pessoas.

Contudo, mesmo no que se refere às grandes personalidades da história, pode-se constatar que a figuração na qual se constituíram oferece a essas personalidades tanto possibilidades quanto limites, na medida em que "as oportunidades entre as quais a pessoa se vê forçada a optar não são, em si mesmas, criadas por essa pessoa. São prescritas e 
limitadas pela estrutura específica de sua sociedade" (Elias, 1994, p. 48).

Esse é um mote importante utilizado por Elias em seu estudo sobre a vida de Mozart. Elias (1995, p. 17-18) investiga a conexão entre a rede das relações em que a personalidade do músico foi moldada, na infância e na adolescência, e o desenvolvimento de seu talento, contrapondo-se, desse modo, à concepção de que a genialidade ou a consciência artística seria uma capacidade inata. Se a noção de "gênio" tende a ser a expressão máxima de uma individualidade associal, que se constitui a partir do núcleo interior de um sujeito, Elias (1994, p. 26) demonstra que o gênio também necessita ser "gerado e partejado por outros seres humanos".

Martuccelli e Singly (2012, p. 44) identificam na obra de Elias afinidades com o pensamento sociológico tradicional, uma vez que o foco das suas análises é sempre a sociedade e as suas figurações; portanto, a sociologia de Elias não 280 pode ser tida como uma variante da sociologia do indivíduo. Não obstante essa afirmação, a perspectiva eliasiana muito influenciou uma das linhas teóricas da sociologia do indivíduo - a vertente disposicionalista - representada pelos trabalhos de Lahire e Kaufmann. No tópico seguinte analisamos alguns dos pontos mais importantes da atualização do pensamento de Simmel e Elias, possibilitada por essa vertente.

\section{Um paralelo entre clássicos e contemporâneos}

Antes de proceder a uma análise da leitura que JeanClaude Kaufmann e Bernard Lahire fazem dos clássicos na tentativa de apreender as relações entre indivíduo e sociedade na contemporaneidade, é importante destacar a interlocução crítica que esses autores estabelecem com a perspectiva teórica de Pierre Bourdieu, considerada como uma referência central na análise das práticas sociais, a partir da qual os autores constroem seus respectivos enfoques teóricos. 
Bourdieu busca superar as dicotomias encontradas nas ciências sociais - entre objetivismo e subjetivismo, indivíduo e sociedade, agência e estrutura - a partir da construção de uma perspectiva disposicionalista da prática, que integra as disposições subjetivas, socialmente adquiridas por meio do habitus, às condições objetivas, caracterizadas pela posição relativa no espaço social. De acordo com o autor, é o caráter intrinsecamente duplo da realidade, que inclui tanto propriedades materiais quanto propriedades simbólicas - que nada mais são do que as propriedades materiais quando percebidas como propriedades distintivas -, que implica a necessidade de superação dessas dicotomias na ciência social em favor de uma perspectiva teórica que englobe ambos os enfoques. Segundo Bourdieu (2013, p. 87), para superar tal oposição, faz-se necessário retornar à prática, como lugar da dialética entre os habitus e as estruturas.

Nesse sentido, o habitus desponta como conceito fundamental para forjar uma teoria disposicional da prática que busca reintroduzir na perspectiva estruturalista a capacidade inventiva dos agentes sem cair numa abordagem intelectualista do indivíduo autossuficiente que busca seus interesses racionalmente estabelecidos. Além disso, tal conceito é pensado por Bourdieu (2013) em termos de classes sociais, considerando que condicionamentos semelhantes produzem habitus semelhantes, que embora sejam irredutíveis em sua diferença específica podem ser apreendidos pela ciência a partir das regularidades observadas - tais como probabilidades de acesso aos recursos de valor de uma sociedade.

Lahire e Kaufmann mantêm a preocupação de Bourdieu em libertar as ciências humanas e sociais das interpretações racionalista e individualista do indivíduo, a partir de uma perspectiva que revela a fabricação social dos indivíduos por meio da incorporação de disposições. No entanto, para os autores, a teoria do habitus termina por conferir precedência explicativa às condições objetivas na explicação da 
ação social, mostrando-se insuficiente para pensar os processos de individuação característicos das sociedades contemporâneas, visto que ele enfatiza a unidade do habitus e um ajuste quase perfeito entre condições objetivas e disposições subjetivas. $\mathrm{O}$ modelo do personagem social alcança toda a sua sofisticação no pensamento de Bourdieu, no qual a posição do indivíduo no espaço social, mediada pela atuação do habitus (princípio gerador e unificador das disposições), explicaria o conjunto das suas práticas, percepções e representações.

Lahire e Kaufmann se fundamentam nos insights contidos no pensamento de Simmel e Elias na tentativa de superar as lacunas da teoria bourdieusiana em direção a uma sociologia disposicional que integra as dimensões individuais na análise das práticas sociais. Dentre os temas mais importantes presentes nos dois autores clássicos e que serão retomados pela vertente disposicionalista da sociologia do 282 indivíduo, destacam-se a análise: (1) dos círculos sociais; (2) do trabalho do indivíduo sobre si mesmo; (3) do processo de internalização das disposições; e, por fim, (4) da conexão entre os processos de sociogênese e psicogênese.

A principal crítica realizada por Lahire e Kaufmann à perspectiva de Bourdieu diz respeito aos seus limites para explicar o processo de incorporação de novas disposições pelos indivíduos, considerado cada vez mais intenso nas sociedades contemporâneas. Nessa perspectiva, Lahire (2002, 2005) critica o caráter de caixa preta do habitus e defende a construção de uma sociologia disposicional que ultrapasse a mera invocação do passado incorporado, reconstruindo a gênese das disposições, seus mecanismos de inculcação, bem como as modalidades de atualização desse passado. Para tanto, o autor propõe um programa de sociologia à escala individual, que possibilita o estudo do social em sua forma internalizada, refratado num corpo individual, que atravessa instituições, grupos e campos de 
luta diferentes. De modo semelhante, Kaufmann tenta desvendar os mecanismos de incorporação das disposições por meio de uma análise centrada no indivíduo.

Além disso, os autores criticam a concepção do habitus como princípio gerador de todas as práticas, caracterizado por disposições homogêneas, sistemáticas, duráveis e transponíveis. Para eles, tal caracterização estaria mais conforme à análise das sociedades tradicionais, pouco diferenciadas, nas quais os processos de socialização que o indivíduo atravessa ao longo da vida são relativamente homogêneos. No entanto, as sociedades contemporâneas se caracterizam por condições de vida heterogêneas, responsáveis pela produção de um ator plural, marcado pela incorporação de disposições múltiplas, heterogêneas e até mesmo contraditórias em seu interior.

Essa noção do indivíduo portador de disposições múltiplas e plurais está fortemente atrelada à formulação simmeliana dos círculos sociais. Para Kaufmann (2003) e Lahire (2002), as sociedades contemporâneas se caracterizam pela multiplicação dos círculos sociais nos quais o indivíduo atua. Na medida em que o indivíduo participa de uma pluralidade de esferas sociais e vivencia processos de socialização plurais, ele, inevitavelmente, internaliza esquemas de ação ou hábitos heterogêneos e até mesmo contraditórios.

Uma consequência da atuação do indivíduo nesses múltiplos círculos é que algum grau de divergência entre hábitos torna-se inevitável. Nesse sentido, outro tema simmeliano que ressurge fortemente na obra desses dois autores é o do trabalho do indivíduo sobre si mesmo. Kaufmann e Lahire concordam com Simmel quando este afirma que se, por um lado, o pertencimento do indivíduo a uma pluralidade de círculos sociais potencializa a eclosão de conflitos tanto internos como externos, por outro lado, esse pertencimento também reforça a busca por uma unidade frente a esses elementos múltiplos. É essa possibilidade de "trabalhar 
sobre si mesmo" tão enfatizada por esses teóricos do indivíduo que faz que o retrato desse indivíduo de disposições plurais da contemporaneidade não seja o de um ator social em estado de conflito permanente e incapaz de engatar uma ação no mundo social.

Como consequência do trabalho sobre si mesmo e das próprias condições heterogêneas de socialização em múltiplos contextos sociais, há um maior espaço para a reflexividade, em contraposição ao caráter marcadamente pré-reflexivo do habitus de Bourdieu. Segundo Kaufmann (2003, p. 296), à medida que os papéis sociais já não definem tanto as práticas sociais, como no passado, é necessário que os atores se comportem de maneira mais reflexiva. À maneira do indivíduo blasé de Simmel, o autor explica que nas sociedades contemporâneas, "o indivíduo vê oferecerem-se-lhe papéis cada vez mais numerosos, dissonantes com seu patrimônio de hábitos, ele mesmo heteróclito, enquanto frag284 mentos da sua rede cognitiva dividida imaginam combinações previstas".

Vale ressaltar, no entanto, que a reflexividade não é pensada nos moldes de uma perspectiva racionalista e individualista, segundo a qual esta emergiria como capacidade do indivíduo, capaz de mudar o curso da ação. Pelo contrário, a reflexividade emerge das contradições do social, de processos de socialização contraditórios. Segundo Kaufmann (2003, p. 176), a reflexividade atua não pela oposição aos hábitos, impondo o poder do pensamento contra os esquemas incorporados, mas fazendo opções no conflito entre esquemas, reformulando as disposições que irão determinar as condutas futuras. A reflexividade emerge sob a forma de um novo esquema que o indivíduo tenta incorporar para libertar a ação e baixar a pressão mental.

Kaufmann (2003) desenvolve essa questão demonstrando que os processos de interiorização dos hábitos operam em níveis distintos, o da internalização e o da 
incorporação, ou seja, "por uma parte, uma interiorização constante, aberta e essencialmente consciente, e por outra, por uma incorporação mais profunda, mais durável, menos consciente, porém mais constitutiva da coerência do indivíduo" (Martuccelli e Singly, 2012, p. 56). Se, no nível da internalização, os indivíduos se caracterizam pela multiplicidade de esquemas de ação, chegando a possuir a sociedade inteira dentro deles, no nível dos hábitos efetivamente incorporados, que tendem a estruturar as suas ações, é possível delinear as linhas de coerência que constituem a sua individualidade.

Já em Lahire (2002, p. 41), a contradição entre esquemas de ação no indivíduo é solucionada na medida em que ele pode ativar/suspender suas disposições de acordo com os diferentes contextos sociais em que ele atua. Ele afirma que os repertórios de esquemas de ação podem coexistir pacificamente quando se exprimem em contextos sociais diferentes, ou ocasionar conflitos limitados. Assim, o indivíduo pode inibir disposições em uma determinada interação social e reativá-las em outra. O autor também busca apreender a natureza dos hábitos reflexivos que, segundo ele, são muito mais comuns do que Bourdieu previu e não cessam de se encadear na vida cotidiana dos indivíduos - ao lado do ajustamento pré-reflexivo do senso prático - planejando e organizando a ação. De acordo com Lahire (2002), o processo de socialização escolar é de fundamental importância para garantir esse distanciamento com relação à prática, característico dos hábitos reflexivos, através dos seus inúmeros exercícios e instrumentos de objetivação da linguagem.

Diante da insuficiência do habitus para pensar a reflexividade dos atores sociais, bem como o caráter contraditório e até mesmo heterogêneo das disposições, tanto Kaufmann quanto Lahire adotam o conceito de hábito, entendido como esquema operatório de ação (Kaufmann, 2003) mais aberto e flexível do que as disposições duráveis 
e transponíveis que caracterizam o habitus. Embora esse último conceito também envolva algum grau de tensão e desajuste entre as disposições do indivíduo e as condições objetivas, apreendidos a partir da noção de histerese, tais casos são considerados como anomalias, que não integram o enfoque teórico do autor (Martuccelli e Singly, 2012).

$\mathrm{Na}$ contramão da perspectiva bourdieusiana, a contradição está no centro da definição do hábito, segundo os enfoques teóricos de Lahire e Kaufmann. No entanto, é importante destacar que esses autores também mantêm diferenças entre si no que se refere à definição do conceito de hábito. Enquanto Lahire utiliza tal conceito para se referir ao conjunto de hábitos reflexivos e pré-reflexivos, Kaufmann afirma que tal definição termina por diluir a reflexividade no conjunto dos esquemas, sem considerar o papel preciso que a mesma cumpre na estruturação da ação. Portanto, esse último aborda o hábito como os esquemas 286 que já foram incorporados, enquanto a reflexividade atua no conflito entre esses esquemas, no momento de interiorização de um novo esquema.

No que se refere à obra de Elias, Lahire e Kaufmann compartilham da sua crítica à concepção de homo clausus, do indivíduo encerrado em si mesmo, afirmando que o processo de fabricação do indivíduo só ocorre por meio da incorporação de disposições e que tal processo é integralmente social (Kaufmann, 2003, p. 165). Assim, tal como nos autores clássicos apresentados nesse texto, nos teóricos da sociologia do indivíduo, a individualidade e as relações sociais não são concebidas como antitéticas.

Se Martuccelli e Singly (2012) afirmam que a obra de Elias não pode ser considerada uma sociologia do indivíduo, Lahire (2005) a concebe como uma formulação, ainda que incipiente, da vertente disposicional dessa sociologia. Para ele, no seu estudo sobre Mozart, Elias demonstra o processo de aquisição de disposições, na família, em primeira 
instância, e nos demais círculos sociais aos quais ele se integrou, que o tornaram um músico excepcional. Tal estudo abordaria os mecanismos envolvidos no processo de "transmissão cultural" que, diferentemente da transferência de uma herança material, caracteriza-se como um processo de longa duração, pois requer a instalação progressiva de hábitos (mentais, gestuais e sensoriais) no indivíduo.

Lahire (2004) segue a pista deixada por Elias, destacando a centralidade das relações familiares de interdependência na constituição de disposições, em alguns de seus estudos empíricos. $\mathrm{O}$ autor afirma que muitas vezes a forma da relação de interdependência assume precedência explicativa na compreensão do surgimento de determinadas disposições nos indivíduos, em detrimento do volume e da estrutura dos capitais (econômico e cultural) que caracterizariam sua posição de classe.

Do mesmo modo, a proposta de Elias de integrar sociogênese e psicogênese na análise da vida social é mantida pelos teóricos da sociologia do indivíduo, interessados no estudo de um indivíduo que é estruturalmente fabricado em um período sócio-histórico específico. Tanto para Kaufmann como para Lahire, nas sociedades contemporâneas, o tipo social de individualidade é aquele constituído por disposições mais abertas e flexíveis em oposição às disposições duráveis e transponíveis do indivíduo bourdieusiano.

Não obstante esses pontos de continuidade, uma importante diferença entre os dois clássicos analisados neste trabalho e a vertente da sociologia do indivíduo desenvolvida por Kaufmann e por Lahire deve ser mencionada. Simmel e Elias elaboram análises mais atentas às consequências negativas para a individualidade, decorrentes da complexificação da sociedade moderna mediante seus fenômenos característicos, o avanço da economia monetária e da divisão do trabalho e a intensificação do controle dos instintos. Basta mencionar o indivíduo dominado pela atitude blasé 
de Simmel, que tem a sua capacidade de se ater às qualidades específicas dos objetos enfraquecida devido às consequências da vida na metrópole e da economia monetária, ou mesmo a sua análise sobre a tragédia da cultura, de acordo com a qual os conteúdos da cultura objetiva se desenvolvem em marcha muito mais acelerada que a cultura interna dos indivíduos. Já em Elias, temos a análise de como a intensa repressão dos instintos no avançado estágio do processo civilizador tem desembocado em uma verdadeira cisão entre a individualidade e o social, de modo que a própria noção de um eu-puro e da individualidade como núcleo natural do indivíduo emerge desse momento marcado por uma forte tensão entre as demandas sociais e os instintos.

Diferentemente desses clássicos, Lahire e Kaufmann parecem ser mais otimistas em relação ao tipo de individualidade que emerge na modernidade avançada, bem como à acentuação da reflexividade dos indivíduos, propiciada 288 nesse período. Eles enfatizam a capacidade do indivíduo de trabalhar sobre si mesmo e atuar no mundo social mesmo quando caracterizados pelas disposições múltiplas e plurais. Na obra dos dois autores, os casos de "clivagem do eu" despontam como os casos de crise aguda, visto que duas lógicas identitárias dissonantes atuam dentro do mesmo indivíduo, levando a um conflito interno que se manifesta em várias situações da existência. Mas, como Lahire (2002) reitera, nem todos os indivíduos que vivenciam socializações em universos contraditórios exibem essas identidades clivadas. Elas são, portanto, casos raros, seja devido aos diferentes níveis de internalização das disposições (Kaufmann) ou aos diferentes contextos sociais nos quais tais disposições são atualizadas (Lahire).

Longe de ser ontologicamente cindido e plural, como em algumas concepções pós-estruturalistas, nessa vertente da sociologia do indivíduo, o ator plural é considerado como o resultado final do social. $\mathrm{O}$ indivíduo não consiste 
no ponto de partida, como no individualismo metodológico, mas no ponto de chegada da análise sociológica. $\mathrm{Na}$ verdade, para essa vertente, o indivíduo é o objeto mais complexo a ser explicado pela sociologia, dada a propriedade de interiorização das disposições múltiplas e plurais que fizeram implodir o modelo do personagem social presente na maior parte do desenvolvimento da sociologia, dos clássicos até as construções teóricas do final dos anos 1950. No entanto, percebe-se que mesmo no que tange a uma corrente teórica fortemente crítica à história da disciplina, é possível identificar importantes elementos de continuidade com os autores clássicos, como Simmel e Elias, para os quais o indivíduo já figurava como um objeto privilegiado de investigação sociológica.

\section{Ana Rodrigues Cavalcanti Alves}

é doutoranda em Sociologia pelo Programa de Pós-Graduação em Sociologia da Universidade Federal de Pernambuco (UFPE) e professora temporária do Departamento de Sociologia da UFPE.

\section{Louise Claudino Maciel}

é doutoranda em Sociologia pelo Programa de Pós-Graduação em Sociologia da Universidade Federal de Pernambuco (UFPE).

\section{Bibliografia}

BAEHR, P. 2002. Founders, classics, canons: modern disputes over the origins and appraisal of sociology's heritage. New Jersey: Transaction Publishers. BOURDIEU, P. 1990. Coisas ditas. São Paulo: Brasiliense. 2008. A distinção: crítica social do julgamento. São Paulo: Edusp. 2013. O senso prático. Rio de Janeiro: Vozes.

EHRENBERG, A. 2010. O culto da performance: da aventura empreendedora à

depressão nervosa. São Paulo: Ideias \& Letras.

ELIAS, N. 1994. Sociedade dos indivíduos. Rio de Janeiro: Zahar. 1995. Mozart, sociologia de um gênio. Rio de Janeiro: Zahar. 
2011. O processo civilizador: uma história dos costumes. Rio de Janeiro:

Zahar. v. 1

KAUFMANN, J. C. 2003. Ego: para uma sociologia do indivíduo. Lisboa:

Instituto Piaget.

LAHIRE, B. 2002. O homem plural. Petrópolis: Vozes.

2004. Retratos sociológicos: disposições e variações individuais. Porto Alegre, Artmed.

. 2005. Patrimónios individuais de disposições: para uma sociologia à escala individual. Sociologia, Problemas e Problemáticas, n. 49, pp. 11-42.

MARTUCCELLI, D. 2007. Cambio de Rumbo: la sociedad a escala del individuo. Santiago: Lom Ediciones.

MARTUCCELLI, D.; SINGLY, F. 2012. Las sociologías del individuo.

Santiago: Lom Ediciones.

NISBET, R. 1980. Conservantismo. In: BOTTOMORE, T. NISBET, R.

(orgs.). História da análise sociológica. Rio de Janeiro: Zahar Editores.

PYYHTINEN, O. 2010. Simmel and the "social". Basingstoke, UK: Palgrave

Macmillan.

SIMMEL, G. 1977. Filosofia del dinero. Madrid: Instituto de Estudios

Políticos.

1983. Questões fundamentais de sociologia. In: FILHO, E. M.

290 (org.), Sociologia. São Paulo: Ática. 1987. A métropole e a vida mental. In: VELHO, G. (org.). $O$

fenômeno urbano. Rio de Janeiro: Guanabara.

2005. O indivíduo e a liberdade. In: SOUZA, J.; OELZE, B.

(orgs.). Simmel e a modernidade. Brasília, DF: UNB.

. 2009. The intersection of social circles. In: SIMMEL, G. Sociology:

inquiries into the construction of social forms. Boston: Brill.

VAN KRIEKEN, R. 1998. Norbert Elias: key sociologists. London: Routledge.

VANDENBERGHE, F. 2005. As sociologias de Georg Simmel. São Paulo:

Edusp; Belém: Edufa.

WAIZBORT, L. 2001. Elias e Simmel. In: WAIZBORT, L. (org.). Dossiê

Norbert Elias. São Paulo: EDUSP. 


\title{
A INDIVIDUALIDADE EM SIMMEL E ELIAS: CONTRIBUIÇÕES TEÓRICAS PARA UMA SOCIOLOGIA DO INDIVÍDUO
}

\author{
ANA RODRIGUES CAVALCANTI ALVES \\ LOUISE CLAUDINO MACIEL
}

Resumo: Este trabalho visa discutir a noção de individualidade no pensamento de Georg Simmel e de Norbert Elias, analisando suas contribuições para o desenvolvimento de uma perspectiva teórica contemporânea que coloca o indivíduo no centro da análise sociológica. Para tanto, faz-se necessário apresentar as concepções epistemológicas dos autores, que buscam desenvolver uma alternativa à dicotomia entre indivíduo e sociedade, a partir de uma perspectiva relacional do social. Em seguida, é possível apresentar suas respectivas concepções de individualidade, destacando suas semelhanças e possíveis diferenças. Por fim, discutiremos de que maneira Bernard Lahire e Jean-Claude Kaufmann recuperam os insights contidos nos clássicos para pensar processos de individualização nas sociedades contemporâneas.

Palavras-chave: Individualidade; Simmel; Elias; Lahire; Kaufmann.

\section{INDIVIDUALITY IN SIMMEL AND ELIAS: THEORETICAL CONTRIBUTIONS FOR A SOCIOLOGY OF THE INDIVIDUAL}

Abstract: This article aims to discuss the notion of individuality proposed by Georg Simmel and Norbert Elias, analyzing their contributions to develop a contemporary theoretical perspective, which places the individual at the center of the sociological analysis. Therefore, the article presents epistemological conceptions from both authors, who intend to develop an alternative idea to the dichotomy between individual and society, from a relational perspective of the social. Subsequently it is possible to present their conceptions of individuality, in order to highlight their similarities and possible 
differences. Finally, the purpose of this article is to discuss how Bernard Lahire and Jean-Claude Kaufmann retrieve insights from the classic authors to think through individualization in contemporary societies.

Keywords: Individuality; Simmel; Elias; Lahire; Kaufmann.

Recebido: 11/12/2015 Aprovado: 10/03/2017 